\title{
Rare Association of Glitoromegaly and Gonadal Dysgenesis with Ataxia Telangiectasia
}

\section{JCR \\ Prashant Patil, Rahul Jahagirdar, Kavita Srivastava}

Division of Pediatric Endocrinology, Department of Pediatrics, Bharati Vidyapeeth

University Medical College, Pune, Maharashtra, India.

\section{Abstract:}

Ataxia-telangiectasia (AT) is an autosomal recessive, multisystem disorder characterized by progressive neurologic impairment, cerebellar ataxia, immunodeficiency and propensity for recurrent sinopulmonary infections. The primary defect is mutation of ATM gene leading to defective signal transduction in case of DNA damage. The authors here report a 13 year old girl having 46 XX karyotype and negative SRY gene with severe failure to thrive, spasticity, bulbar telangiectasia, clitoromegaly and gonadal dysgenesis. Child had hypoplastic uterus with non-visualization of ovaries on MRI pelvis. The diagnosis of ataxia-telangiectasia (AT) was confirmed with very high levels of alfa-fetoprotein (AFP). Association between clitoral hypertrophy in case of AT is rare but in our case it could be explained on the basis of gonadal dysgenesis.

Key words: Ataxia-Telangiectasia, Cerebellar Ataxia, Gonadal Dysgenesis, Turner Syndrome, Uterus.

\section{Introduction}

Ataxia-telangiectasia (AT) is a rare, genetic disorder first described by Louis and Bar in 1941, characterized by immunodeficiency and neurodegeneration with increased tendency for recurrent sinopulmonary infections [1], malignancy and autoimmune diseases [2]. Literature describes endocrine abnormalities as rare associations. Here we describe a rare association of gonadal dysgenesis and clitoromegaly in a girl with AT.

\section{Case Report}

A 13 year old girl born as first of the twins (other twin asymptomatic) to non-consanguineous parents presented with failure to thrive since 8 years, per vaginal discharge since 4 years, difficulty in standing and walking from last 2 years and progressive swelling over genital region since last month. Child was born as small for gestational age (SGA) with birth weight of $1.5 \mathrm{~kg}$. She had progeric facies, and severe emaciation. Her weight and height was $12.7 \mathrm{~kg}$ and $117 \mathrm{~cm}$ (both below $3^{\text {rd }}$ percentile as per IAP growth charts) [3]. Telangiectasias were noted on bilateral bulbar conjunctiva [Fig.1]. Neurological abnormalities consisted of hypertonia with spasticity, nystagmus and dysmetria. Child had erythematous clitoral hypertrophy [Fig.2] along with foul smelling genital ulceration with discharge. Her sexual maturity rating (SMR) was prepubertal.

Corresponding Author: Dr. Prashant Patil

Email: dr_prash4u@yahoo.com

Received: October 31, 2015 | Accepted: February 1, 2016 | Published Online: February 20, 2016

This is an Open Access article distributed under the terms of the Creative Commons Attribution License (creativecommons.org/licenses/by/3.0)

Conflict of interest: None declared | Source of funding: Nil | DOl: http://dx.doi.org/10.17659/01.2016.0019 
Examination of external genitalia under general anaesthesia showed hypertrophied clitoris with prominent dorsal hood with urogenital sinus with ulceration. Her haematological and biochemical investigations including hemogram, electrolytes, HIV and hepatitis $B$ were normal. Her gonadotropins were prepubertal (FSH: $0.83 \mathrm{mlU} / \mathrm{mL}$ and $\mathrm{LH}: 0.03$ $\mathrm{mlU} / \mathrm{mL}$ ) probably due to chronic systemic disease and possible pituitary involvement. Hormonal workup for congenital adrenal hyperplasia was negative (17-OHP: $0.66 \mathrm{ng} / \mathrm{mL}$, ACTH: $57.9 \mathrm{pg} / \mathrm{mL}$, Testosterone: $0.83 \mathrm{pg} / \mathrm{mL}$ ) and karyotype was normal female (46XX). MRI of pelvis was suggestive of hypoplastic uterus, absent ovaries. Her MRI brain revealed marked cerebellar atrophy and $\mathrm{FISH}$ for SRY gene was negative. Diagnosis of ataxia telangiectasia was confirmed by high levels of AFP (serum AFP: $495 \mathrm{ng} / \mathrm{mL}$ (normal upto $10 \mathrm{ng} / \mathrm{mL}$ ).

\section{Discussion}

AT is a rare autosomal recessive multi-system disorder caused by mutation in the ataxia-telangiectasia mutated gene (ATM). ATM is a large serine/threonine protein kinase, a member of the phosphoinositide 3-kinase-related protein kinase (PIKK) family whose primary function is control of signal transduction for the DNA damage response [4]. AT syndrome is associated with cyto- and nucleomegaly in several organ systems and it makes individuals prone for various autoimmune diseases, sinopulmonary infections and malignancy. Failure to thrive due to various endocrine abnormalities such as Hashimoto's thyroiditis [5], adrenal gland dysfunction [6], primary gonadal failure, ovarian failure and pituitary abnormalities have been reported in association with AT. Association of gonadal dysgenesis with AT is also known [7]. Rare AT patients with $46 \mathrm{XX}$ gonadal dysgenesis associated with premature ovarian failure and clitoromegaly are described in the literature [8]. Ammann et al. in 1970 described one 16 year female with AT who had extremely irregular vaginal bleeding and sexual infantilism [9].

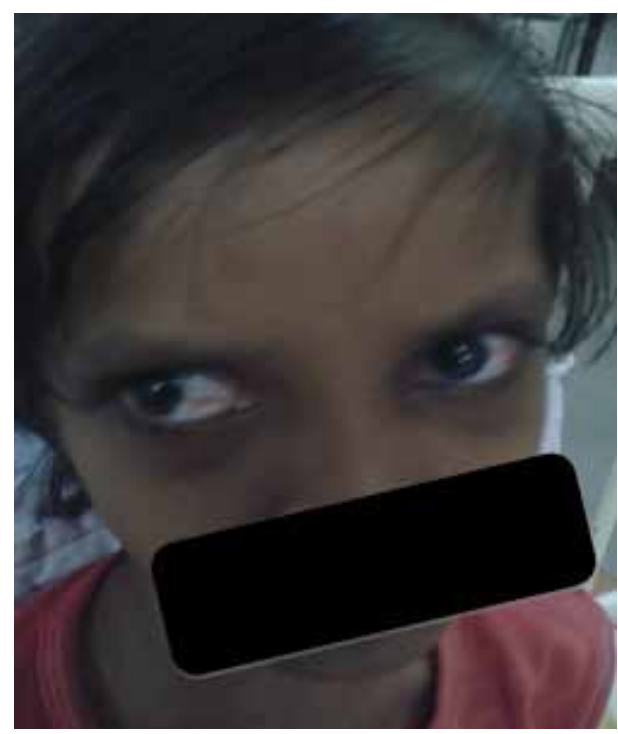

Fig.1: Telangiectasias noted on bilateral bulbar conjunctiva.

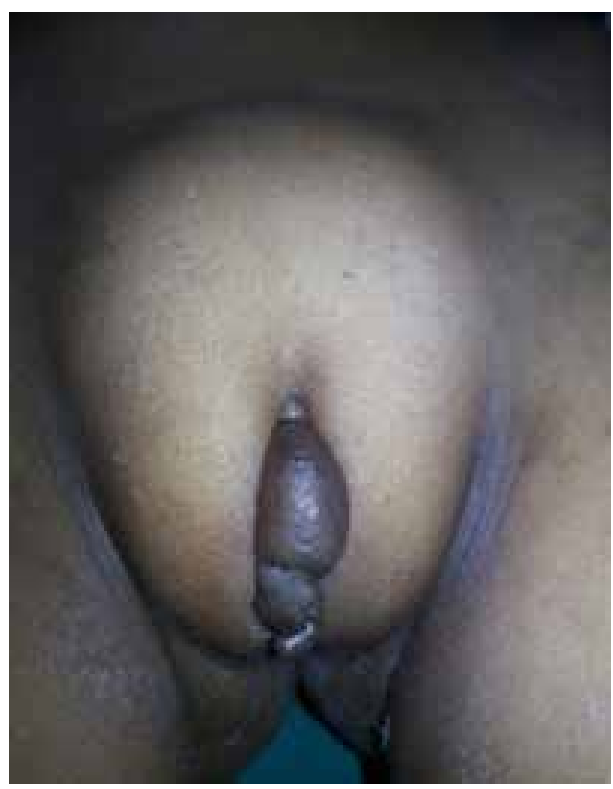

Fig.2: Child had erythematous clitoral hypertrophy.

The absence of ATM gene is shown to deleteriously affect folliculogenesis in mouse mutant as female ATM-deficient mice were sterile with gonadal dysgenesis as a result of a 
defect in meiotic recombination [10] leading to premature ovarian failure. It could also be due to autoantibodies against ovaries themselves, FSH receptors, or $\mathrm{LH}$ receptors. In our case gonadal dysgenesis and clitoral hypetrophy seems to result as a consequence of $46 \mathrm{XX}$ gonadal dysgenesis. Presence of urogenital sinus is an as yet unreported finding in our patient.

\section{Conclusion}

It is important to remember that in a case of atypical genitalia and neurological manifestations, ataxia telangiectasia is a rare but possible cause.

\section{Contributors}

PP: Literature search and review, manuscript preparation, he will act as guarantor. RJ: Editing the manuscript, managed the patient. KS: diagnosed the patient, acquisition and interpretation of data, managed the patient and edited the manuscript. All authors contributed to manuscript and its final approval.

\section{References}

1. Guerra-Maranhao MC, Costa-Carvalho BT, Nudelman V, Barros-Nunes P, CarneiroSampaio MM, Arslanian C, et al. Response to polysaccharide antigens in patients with ataxia-telangiectasia. J Pediatr (Rio J). 2006;82(2):132-136.

2. Leechawengwongs E, Shearer WT. Lymphoma complicating primary immunodeficiency syndromes. Curr Opin Hematol. 2012;19:305312.

3. Khadilkar V, Yadav S, Agrawal KK, Tamboli S, Banerjee $M$, Cherian A, et al. Revised IAP growth charts for height, weight and body mass index for 5- to 18-year-old Indian children. Indian Pediatr. 2015;52(1):47-55.

4. Zhan H, Suzuki T, Aizawa K, Miyagawa K, Nagai R. Ataxia telangiectasia mutated (ATM)-mediated DNA damage response in oxidative stressinduced vascular endothelial cell senescence. J Biol Chem. 2010;285(38):29662-70.

5. Patiroglu T, Gungor HE, Unal E, Kurtoglu S, Yikilmaz A. Hashimoto thyroiditis associated with ataxia telangiectasia. J Pediatr Endocrinol Metab. 2012;25:349-352.

6. Rubchak NV. Study of the function of the adrenal cortex in ataxia telangiectasia (LovisBar syndrome). Pediatriia. 1974;1 1:52-55.

7. Zadik Z, Levin S, Prager-Lewin R, Laron Z. Gonadal dysfunction in patients with ataxia telangiectasia. Acta Paediatr Scand. 1978;67:477-479.

8. Simpson J. XX Gonadal Dysgenesis and Premature Ovarian Failure in 46,XX Individuals. Glob Libr Women's Med. 2008;DOI10.3843/ GLOWM.10355.

9. Ammann AJ, Duquesnoy RJ, Good RA. Endocrinological studies in ataxia-telangiectasia and other immunological deficiency diseases. Clin Exp Immunol. 1970;587-595.

10. Barlow $C$, Hirotsune $S$, Paylor R, Liyanage $M$, Eckhaus $M$, Collins $F$, et al. ATM-deficient mice: a paradigm of ataxia telangiectasia. Cell. 1996;86:159-171. 